Journal of Biomedical Materials Research Part A December 2008, Volume 87A Issue 3, Pages 666 675

http://dx.doi.org/10.1002/jbm.a.31819

(c) 2009 Wiley Periodicals, Inc., A Wiley Company
Archimer, archive institutionnelle de l'Ifremer http://www.ifremer.fr/docelec/

\title{
Potential effects of a low molecular weight Fucoidan extracted from brown algae on bone biomaterial osteoconductive properties
}

\author{
Igondjo Tchen Changotade $\mathrm{S}^{1}$, Korb $\mathrm{G}^{1}$, Bassil $\mathrm{J}^{1}$, Barroukh $\mathrm{B}^{1}$, Willig $\mathrm{C}^{1}$, \\ Colliec-Jouault $\mathrm{S}^{2}$, Durand $\mathrm{P}^{2}$, Godeau $\mathrm{G}^{1}$, Senni $\mathrm{K}^{1, \star}$
}

The first two authors contributed equally to this work.

${ }^{1}$ Laboratoire de physiopathologie des tissus non minéralisés, Faculté de chirurgie dentaire de

Montrouge, Université Paris Descartes, France.

${ }^{2}$ IFREMER, Nantes/Brest Plouzané, France

*Corresponding author : Senni K, email address : senni k@yahoo.com

\begin{abstract}
:
In this work we firstly tested the influence of low molecular weight fucoidan extracted from pheophicae cell wall on bidimensional cultured normal human osteoblasts behaviours. Secondly impregnation procedure with LMW fucoidan of bone biomaterial (Lubboc $®$ ) we explored in this bone extracellular matrix context its capabilities to support human osteoblastic behaviour in 3D culture. In bidimensionnal cultures we evidenced that: LMW fucoidan promotes human osteoblast proliferation, collagen type I expression and favours precocious alkaline phosphatase activity. Furthermore with LMW fucoidan von Kossa's staining was positive at 30 days and only positive at 45 days in absence of LMW fucoidan. In our three dimensional culture models with the biomaterial pretreated with LMW fucoidan osteoblasts promptly overgrew the pretreated biomaterial. We evidenced too osteoblasts increased proliferation with pretreated biomaterial when compared with untreated biomaterial. On control as well as with LMW fucoidan impregnated biomaterial osteoblasts secreted osteocalcin and expressed BMP2 receptor. In conclusion, in our experimental conditions LMW fucoidan stimulated expression of osteoblastic markers differentiation such as alkaline phosphatase activity, collagen type I expression and mineral deposition, furthermore cell proliferation was favoured. These findings suggest that fucoidan could be clinically useful for bone regeneration and bone substitute design.
\end{abstract}

Keywords: Fucoidan, osteoblast, bone, biomaterial, heparan mimetics 


\section{$\underline{\text { Introduction }}$}

Bone substitute materials are largely used in orthopaedic and periodontal surgery for bone reconstruction, filling up defects, or implant integration etc... Finding a perfect bone substitute material for clinical use was the aim of researchers for many decades. Among bone substitutes autograft is considered the best because immune response is abolished and competent bone cells are still present in the grafted material [1]. Unfortunately this autologous material is limited in volume and surgical procedures increase operating time and donor site morbidity risk [2]. For these reasons clinicians have turned towards alternative materials such as allografts, synthetic materials or xenogenic bone substitutes.

Allografts are used commonly and exhibit very good osteo-integration, but samples submitted to minimal treatment (freezing, antibiotics) before grafting must be strictly controlled for bacterial or virological infections this leading to high financial costs [3]. Synthetic materials were also proposed but are not used in loading site owing to their poor mechanical properties.

Acellular xenogenic resorbable substitutes of bovine origin appear to be an interesting alternative owing to their mechanical properties and porosity close to human bone and to a non pyrogenic and non antigenic material generating process [4]. For example Lubboc® (Transphyto SA, Ost-Developpement Clermont-Ferrand, France) is a resorbable highly purified cancelous bone substitute from a bovine source used in orthopaedic and periodontol surgery procedures. Chemical and physical purification processes allow preservation of the bone mineralized fibrillar collagenous scaffold only.

These materials are considered osteoconductive and serve as scaffold for new bone ingrowth. Bio-integration of the xenogenic material depends on the capacity of the bone cells from the host to migrate into the biomaterial, to proliferate and to ensure the remodelling of 
the bone matrix. Unfortunately the purification process which preserves mineral fibrillar collagenous scaffold, eliminates all other bone matrix proteins and thus the capacity of biomaterial to retain growth factors such as BMPs or FGFs (crinopexy) [5]. This could explain better osteo-integration capability of bone allograft compared with highly purified xenogenous bone material. As a result, it would be interesting to restore the capabilities of this collagenous purified scaffold to trap growth factors.

Use of fucoidans, sulphated polysaccharides from pheophicae cell wall, could be an attractive alternative. After extraction and acidic hydrolysis or free radical depolymerization [6], low molecular weight fractions of fucoidans (LMW fucoidan, <30kDa) were shown to exhibit numerous heparan sulphate properties without strong anticoagulant activities as shown for heparin [7].

For example LMW Fucoidans are potent inhibitors of connective tissue breakdown [8], promote fibrillar collagen matrix formation by cultured fibroblasts [9], support fibroblastic proliferation [9], and stimulate in vitro and in vivo angiogenesis [10],[11]. These properties are essentially due to the capability of LMW fucoidans to provide protection and signal promotion to heparin binding growth factors such as FGFs, or VEGFs [12], [13]. Thus Low molecular weight fucoidans are proposed as tissue regenerating agent which could improve material biocompatibility.

The aim of our work was to study LMW fucoidan effects on normal human osteoblast differentiation in two dimensional cultures, and to investigate the behaviour of these cells cultured in tri-dimension with Lubboc ${ }^{\circledR}$ after impregnation or not of the biomaterial with LMW fucoidan. 


\section{Materials and methods}

\section{$\underline{\text { Cell culture }}$}

Osteoblast isolation and culture

Human osteoblast cells (HOBs) were isolated from trabecular bone in two patients one male aged 27 and one female aged 39 undergoing hip joint replacement surgery after a traffic accident. Bone materials were obtained after informed consent of the patients according to the Declaration of Helsinki. Alveolar bone chips $(3 \times 3 \times 3 \mathrm{~mm})$ were harvested and thoroughly washed in phosphate-buffered saline (PBS) and placed on culture dishes with Dubelcco's modified Eagle's medium (DMEM) dropped on each tissue fragment for 2 hours. DMEM contained $2 \mu \mathrm{g} / \mathrm{mL}$ fungizone, antibiotics $(100 \mathrm{U} / \mathrm{mL}$ penicillin, $100 \mu \mathrm{g} / \mathrm{mL}$ streptomycin) and $20 \%$ fetal calf serum. The culture dishes were then placed at $37^{\circ} \mathrm{C}$ and $5 \% \mathrm{CO}_{2}$ in a heat sterilized incubator. Culture medium (DMEM, 20\% fetal calf serum, penicillin, streptomycin, fungizone) was renewed each 3 days. At day 5 of culture cells migrated from bone chips and reached confluence in 4 weeks.

\section{Osteoblast culture in 2 dimensions}

Confluent human osteoblasts were seeded (after trypsin treatment) at $10^{4}$ cells per well in a 24 well plate during 24 hours with DMEM containing $10 \%$ fetal calf serum, penicillin $(100 \mathrm{U} / \mathrm{mL})$, streptomycin $(100 \mu \mathrm{g} / \mathrm{mL})$. After cell adhesion the culture medium was renewed and low molecular weight fucoidan was added $(10 \mu \mathrm{g} / \mathrm{mL})$ or not. We conducted in a previous work osteoblast cultures with $1 \mu \mathrm{g} / \mathrm{mL}, 10 \mu \mathrm{g} / \mathrm{mL}$ and $100 \mu \mathrm{g} / \mathrm{ml}$ of fucoidan, in which we observed that with $10 \mu \mathrm{g} / \mathrm{mL}$ of fucoidan the proliferation of osteoblasts were optimal For this reason this concentration was used in this work. Culture medium was renewed each three days and LMW fucoidan was added in the culture medium every three days. At day 21, osteogenic induction was conducted through supplemented media with $100 \mathrm{nM} \beta$ glycerophosphate and $25 \mathrm{mM}$ ascorbic acid. After 8, 15, 30 and 45 days of culture cells were treated with trypsinEDTA for cell counting (counter Coulter) or fixed with absolute ethanol $\left(-20^{\circ} \mathrm{C}\right)$ for morphological, histological and immunodetection studies. 
Morphological, histological and indirect immunodetection studies

-After ethanol fixation, cultured cells were stained during 2 minutes with GIEMSA solution (Merck) then washed before microscope observation. Cell nuclei appeared blue-black and cytoplasm blue-light.

-Von Kossa's technique was used to evidence calcium deposits. Briefly, osteoblasts culture after washing in distilled water was covered with $5 \%$ silver nitrate during 30 minutes in darkness. After exhaustive washing with tap water then distilled water, cell cultures were exposed to bright sun light for 1 hour, before microscope observation. Calcium deposits appeared black.

-Detection of alkaline phosphatase activity: Osteoblasts cultures were brought to distilled water and covered with Michaeli's Veronal Hydrochloric acid buffer pH 9.2 containing $0.1 \%$ sodium alpha naphtol phosphate and $0.1 \%$ Fast Red during 1 hour at room temperature then washed in running water for 2 minutes before microscope observation. Sites of enzyme activity appear in brown.

-Indirect immunodetection of collagen type : Osteoblasts cultures were rinsed in PBS then incubated with $3 \% \mathrm{H}_{2} \mathrm{O}_{2}$ during 5 minutes, washed in PBS. After blocking of non specific antigenic sites with $0.1 \%$ defated milk during 10 minutes cells were incubated with primary antibody (mouse monoclonal anti human collagen type I (Sigma) dilution 1/40) during 1 hour and subsequently with secondary antibody (HRP goat anti mouse IgG, dilution 1/60, Calbiochem) during 30 minutes. Peroxydase activity was detected using 33'diaminobenzidine tetra hydrochloride (Sigma) in Tris-HCl buffer $\mathrm{pH}$ 7.4-7.6 for 10 minutes in dark. Negative controls were incubated with inappropriate secondary antibody or by omitting primary antibody.

\section{$\underline{\text { Tri dimensional osteoblast cultures on bone biomaterial (Lubboc) }}$}

Bone biomaterial

The bone biomaterial (Lubboc®) from Transphyto SA (Clermont-Ferrand, France) was obtained by the manufacturer from calf femoral condyles after appropriate treatments (washing, defatting, urea treatment....) patent PCT/WO/91/07/94. This purified mineralized collagen matrix is commercially available (Lubboc®). Samples of bone biomaterial $(4 \mathrm{~mm} \times 4 \mathrm{mmx} 4 \mathrm{~mm})$ were rehydrated and pre incubated in a serum free culture medium at $37^{\circ} \mathrm{C}$ in $95 \%$ air and $5 \% \mathrm{CO}_{2}$ for 1 hour. Pre-incubating medium was removed and osteoblasts 
were seeded $\left(2.10^{4}\right.$ cells/ bone biomaterial) in DMEM containing $10 \%$ fetal calf serum, transferrin $(10 \mu \mathrm{g} / \mathrm{mL})$, insulin $(5 \mu \mathrm{g} / \mathrm{mL})$. Before cell seeding bone biomaterials were immersed in PBS containing 40mg/mL of LMW fucoidan during 6 hours or without LMW fucoidan (control experiment).

After 8, 15, 30 and 45 days cultured bone biomaterials were fixed in cold $\left(4^{\circ} \mathrm{C}\right) 40 \%$ ethanol (6 hours) dehydrated in increasing ethanol solution and embedded without demineralisation in methyl methacrylate (Merck, Germany). They were then sectioned with a polycut E microtome (Leica, Germany) serial sections (4-6 $\mu \mathrm{m}$ thick) were deplastified with 2 baths (25 minutes each) of 2-methoxyethyl acetate (Carlo Erba) then rehydrated with decreasing alcohol solution $(100,70,40,30)$ until water bath.

Morphological investigations

Cultured bone biomaterial sections were stained with toluidine blue $(\mathrm{pH} 3.8)$ or submitted to the same treatment as those exposed in materials and methods for $2 \mathrm{D}$ culture namely: Von Kossa's technique, alkaline phosphatase activity detection and indirect immunodetection of collagen type I using mouse monoclonal anti-human collagen type I (Sigma), and also indirect immunodetection of human BMP2 receptor using mouse monoclonal anti-human Activin RIA ( R \& D Systems ) were performed with appropriated secondary antibody HRP. The observation was done on Zeiss microscope.

Electron scanning microscopy

After 8, 15, 30 and 45 days cultured bone material removed from the culture were washed in cold PBS pH 7.4, fixed in $2.5 \%$ glutaraldehyde in PBS at $4^{\circ} \mathrm{C}$ post fixed in $2 \%$ osmium tetroxide and dehydrated in ethanol series. Samples were then dessicated and mounted on aluminium specimen holder and gold coated with a JOEL JFC-1200 fine coater at $15 \mathrm{~mA}$ for 120s. Viewing was on a JOEL JSM-5600LV scanning electron microscope using an accelerating voltage of $10 \mathrm{kV}-20 \mathrm{kV}$.

Western blotting analysis

After 8, 15, 30 and 45 days of culture, culture media were submitted to westernblotting analysis for osteocalcin.

Electrophoresis was carried out using a mini protean II system (Biorad, France) ten per cent polyacrylamide gels (10 cm height, $1.5 \mathrm{~mm}$ thickness, DURACRYL from Millipore) contained buffered solution consisting of $2.5 \mathrm{~mL} 1.5 \mathrm{M}$ Tris $\mathrm{HCl}$ pH8.8; $100 \mu \mathrm{L}$ SDS 10\%, 
$4 \mathrm{~mL}$ polyacrylamide, and $4 \mathrm{~mL}$ of distilled water $\mathrm{pH} 8.8$; stacking gel contained $4 \%$ polyacrylamide in $0.5 \mathrm{M}$ Tris $\mathrm{HCl} \mathrm{pH}$ 6.8. Gels were polymerised by adding $50 \mu \mathrm{l}$ of $10 \%$ ammonium persulfate and $10 \mu \mathrm{L}$ of $0.1 \%$ TEMED (Biorad, France). Samples were half diluted in $1 \mathrm{M}$ Tris pH6.8 containing $50 \%$ glycerol and $0.4 \%$ bromophenol blue, and gels were run under Laemmli conditions (40mA, 1h).

Gels were transferred $75 \mathrm{mn}(75 \mathrm{~V})$ on polyvinylidene difluoride membrane (Immobilon MILLIPORE) with a transfer buffer containing 20\% methanol, Tris 25mM, glycine 192mM. after blockage of non specific binding sites with $5 \%$ non fat milk for 1 hour at room temperature, blots were incubated with anti-osteocalcin (TEBU) polyclonal antibody diluted 1:750 in PBS for 1 hour at room temperature. Membranes were washed four times during 10 minutes with PBS $0.1 \%$ Tween 20 (vol/vol) (PBS/ Tween) and incubated with peroxidase labelled second antibody diluted 1:1000 in PBS. They were then washed extensively with PBS/Tween, treated with Covalight (Ab-Cys, France) for $1 \mathrm{mn}$ and revealed using KODAK BIOMAX MR film. Multiple exposures were examined to ensure that the results analyzed reflected those produced with linear range of the film. 


\section{Results}

Cultures in two dimensions

Cell proliferation in 2D culture

Cell proliferation was comparable at day 7 of $2 \mathrm{D}$ culture for osteoblasts cultured in the presence of fucoidan $(10 \mu \mathrm{g} / \mathrm{mL})$ when compared with osteoblasts cultured without fucoidan. At this time cell numbers was estimated at: $65000+/-2600$ for control cells and at $54000+/-$ 1700 cells for osteoblasts cultured in the presence of fucoidan (see figure 1). The addition of fucoidan to the osteoblast cultures results in an increase in the cell proliferation from day 7 to day 45 when compared with osteoblasts cultured without fucoidan; thus, at days 15 and 45 cell numbers were estimated at: $116000+/-8400$ and $209000+/-2500$ respectively for osteoblasts cultured in the presence of fucoidan and estimated at $88000+/-220$ and $138000+/-$ 1700 for cells without fucoidan (see figure 1).

Alkaline phosphatase staining

Alkaline phosphatase staining was detected for cell cultures from the $14^{\text {th }}$ day of culture for osteoblasts cultured without fucoidan and from the $7^{\text {th }}$ day for osteoblasts cultured in the presence of fucoidan. The higher staining was observed after 14 days for osteoblasts cultured in the presence of fucoidan then decreased. For osteoblasts cultured without fucoidan alkaline phosphatase activity is detected after 14 days then increased until the end of the culture (see figure 2)

Von Kossa's staining

Until day 30 Von Kossa's staining was negative and few nodules were positive at 45 days for osteoblasts cultured without fucoidan (figure 3a, b).

For osteoblasts cultured in the presence of $10 \mu \mathrm{g} / \mathrm{mL}$ of fucoidan von Kossa's staining was positive at 30 days for few nodules and the staining was intense at 45 days (see figure $3 \mathrm{~d}, \mathrm{e}$ ).

Indirect immunodetection of type I collagen

Indirect immunodetection of type I collagen was positive at 15 days for osteoblasts cultured in the presence of fucoidan as well as for osteoblasts cultured without fucoidan, the labelling being cytoplasmic. Positive immunodetection of type I collagen was observed located at the cell periphery after 45 days for cells cultured without fucoidan (figure $3 \mathrm{c}$ ), this 
labelling being superimposed with von Kossa's positive areas detected after 45 days for cells cultured with fucoidan (figure $3 \mathrm{f}$ ).

Cultures in three dimensions

Scanning electron microscopy

Scanning electron microscopy has shown the organization of the trabecular network of the purified mineralized collagen matrix biomaterial (Lubboc $®)$. At low magnification (fig.4a, G=65) the biomaterial appeared as trabecules connected together with empty interconnected medullar spaces. In figure $4 \mathrm{~b}$ at higher magnification $(G=9600)$ the biomaterial (with or without pre-treatment with fucoidan) appeared with regular arrangement of mineralized collagen bundles.

At 10 days of culture without pre-treatment with fucoidan cells displayed an elongated shape and a disposition similar to the orientation of the rod at the surface of the biomaterial (fig 5a, $\mathrm{G}=350$ ). After pre-treatment with fucoidan at 10 days of culture osteoblasts developed numerous filopodia (fig. $5 \mathrm{~b}, \mathrm{G}=56$ ).

At 30 days of culture the biomaterial surface was covered with cells (fig 5c, G=75), and with the biomaterial pre treated with fucoidan prior to the cell seeding, the surface of the biomaterial was covered with a continuous sheet of oriented cells (fig $5 \mathrm{~d}, \mathrm{G}==75$ ), the medullary space appearing reduced when compared at the same magnification with non fucoidan treated biomaterial prior to cell seeding and osteoblasts made their way into the biomaterial ( fig $5 \mathrm{f}, \mathrm{G}=100$ ).

Cell counting after $3 \mathrm{D}$ culture

At day 8 and day 30 of osteoblast 3D cultures on the biomaterial, after collagenase treatment (Clostridium histolyticum $2 \mathrm{mg} / \mathrm{mL}$ ) the number of cells cultured on the biomaterial without pre-treatment with the fucoidan was estimated at: $8.5 .10^{3}$ cells $/ \mathrm{mm}^{3}$ of biomaterial and $22.10^{3}$ cells $/ \mathrm{mm}^{3}$ of biomaterial at days 8 and 30 of culture (figure $5 \mathrm{e}$ ).

The number of cells cultured on the biomaterial pre treated with fucoidan was estimated at: $8.4 .10^{3}$ cells $/ \mathrm{mm}^{3}$ of biomaterial at day 8 of culture and at: $27.10^{3}$ cells $/ \mathrm{mm}^{3}$ of biomaterial at day 30 of culture (figure $5 \mathrm{e}$ ). 


\section{Indirect immunodetections}

Indirect immunodetection of collagen type I was conducted after embedding of the cultured biomaterial in methyl methacrylate. A net positivity was observed at the periphery of the biomaterial impregnated with the fucoidan cultured with human osteoblast at 30 days of culture ( see fig $6 \mathrm{~b}$ ). This positivity was weak at the same time of culture when the biomaterial was cultured with human osteoblasts without pre-treatment with the fucoidan.( see figure $6 \mathrm{a}$ )

After western blotting analysis osteocalcin was shown to be present in the culture media. Osteocalcin appeared as a band with an apparent molecular mass estimated at about 10kDa. For osteoblast cultured on pre-treated Lubboc with fucoidan the intensity of the labelling decreased regularly with the culture time and was shown light at day 45 of culture. Same observations were made with osteoblasts cultured on non impregnated Lubboc with fucoidan with a time lag, the osteocalcin being detected in the culture media only at day 15 (see figure 7)

Indirect immunodetection of human BMP2 receptor was performed after 7 days of culture for the biomaterial treated or not with fucoidan before 3D cultures with human osteoblasts.

With the biomaterial pre treated with fucoidan after 7 days of culture in the human osteoblasts a net labelling was observed associated with the cells located at the periphery and in the infrastructures of the biomaterial for BMP2 receptor (fig 8). 


\section{Discussion}

LMW fucoidan is a sulphated polysaccharide able to mimic some heparan sulphate properties such as growth factors binding, protection and promotion [12], [13], with weaker bleeding effect [7]. Furthermore anti-proteolytic effects and connective tissue protection have been recently described for this polysaccharide [8]. As heparan sulphate, LMW fucoidan promotes endothelial cells, and dermal fibroblasts proliferation [10], [9], and in vivo neoangiogenesis [11]. LMW fucoidan could then be considered as healing promoter. Therefore this non animal compound could be advantageously used in bone healing. We first tested the influence of this heparan mimetic polysaccharide on bidimensional cultured normal human osteoblasts behaviour.

Sequential kinetics osteoblast differentiation in bidimensional culture [14], [15], [16] is well defined. This differentiation is characterized by cell proliferation, collagenous matrix formation, mineralized nodule formation, expression of alkaline phosphatase activity and osteocalcin.

In bidimensional culture, our results evidenced the capability of LMW fucoidan to promote human osteoblast proliferation that can be explained by serum growth factors protection and promotion. Furthermore, increase of fibrillar collagens in cultured bone cell extracellular matrix by LMW fucoidan was previously observed in fibroblast and smooth muscle cells cultures [9], [17]. In culture, bone cells proliferation and collagen fibrillation are essential for in vitro osteogenic differentiation [16]. These data are in concordance with advanced osteoblasts differentiation with LMW fucoidan, as shown by early peak of alkaline phosphatase activity, early nodule formation, and massive extracellular matrix mineralization observed in the latter phase of $2 \mathrm{D}$ culture.

In the second step of our experiments, we used xenogenic bone cancelous material proposed for bone surgery repair (Lubboc ${ }^{\circledR}$ from Transphyto Ost-Developpement ClermontFerrand, France). This biomaterial consists of purified bone natural mineralized collagenous scaffold considered as apyrogenic and non-immunogenic and biocompatible material [4].

In vitro cultures of osteoblasts in porous materials like ceramics [18] collagen [19] commercial bone substitutes [20] or polymers scaffold [21] were conducted by several groups.

It has been proposed that the porosity of the biomaterial is an important parameter for deep cell colonization of the porous material with a good supply of fluids with nutrient throughout the biomaterial [22]. Our observations are in accordance with these propositions. 
Lubboc according to the manufacturer's information have micropore (100-1000nm) and macropore $(1.5-2 \mathrm{~mm})$ as illustrated on the scanning electron document that we have shown (see fig 1).

By simple impregnation procedure with LMW fucoidan solution $(40 \mu \mathrm{g} / \mathrm{mL})$ we modified this biomaterial to explore in this bone extracellular matrix context its capabilities to support human osteoblastic behaviour.

In our three dimensional culture models, human osteoblasts seeded on to the biomaterial (Lubboc®) pretreated with LMW fucoidan were shown to adhere to the biomaterial, exhibited an elongated shape and were oriented parallel to the collagen bundles. These results suggest that the biomaterial pretreated with LMW fucoidan retains its capacity concerning the adherence osteoblastic cells.

According to the producer's information Lubboc contains $26.0+/-1.5 \%$ of collagen and $63.2+/-0.8 \%$ of mineral. The collagen nature of this biomaterial greatly influences osteoblastic adherence as demonstrated by Basle MF et al [2]. These authors cultured human osteoblast like cells (Saos-2) on two different bovine xenogenic biomaterials which differed in matrix component, the former (Lubboc $\left.{ }^{\circledR}\right)$ being characterized by preservation of the mineralized collagen matrix, the latter by complete deproteinization, only the mineral phase being preserved; both were similar in architectural organisation. Basle MF et al reported that the major integrin of the osteoblasts, the $\beta 1$ subunit known to bind cells and collagen, was localized at the outer surface of osteoblasts in association with collagen bundles of the Lubboc, this attachment being linked to the elongated cells oriented parallel to the collagen bundles while with the deproteinized biomaterial osteoblasts appeared globular and did not adopt any preferential orientation. Our results are in accordance with this study as well as with other studies which reported on the importance of the chemical nature of a bone biomaterial for biointegration of xenogenic implants [23], in particular the collagenic nature of the substitute [24] [25] for cells migration and proliferation [25][26].

Lubboc biomaterial containing well integrated oriented collagen bundles as demonstrated at high magnification with electron microscopic studies (see fig. 1b) favours cell attachment and orientation, this being linked to RGD sequences contained in collagen type I which is specific to the fixation of integrin cells membrane receptor as reported by Grezsik and Robey [26]. With scanning electron microscope we observed that fucoidan pretreated biomaterial was overgrown with osteoblasts. These are important data, considering the possible development of tissue engineered hybrid material which could contain biocompatible osteoconductive materials and competent bone cells for biomedical applications. 
Our observations have shown that, LMW fucoidan impregnation procedure didn't modify cell morphology and cell adhesion on this xenogenic collagenous bone material and cells settled into control biomaterial and also into LMW fucoidan impregnated biomaterial secreted osteocalcin and expressed BMP2 receptor. Furthermore after biomaterial impregnation with LMW fucoidan we observed osteoblast increased proliferation when compared with control biomaterial. This fucoidan mediated phenomen could be essential for tissue integration of processed bone biomaterial. Hartl et al demonstrated in vivo, in human, a faster integration of allograft than Lubboc [27]. These data exhibit the importance of biomaterials microenvironment: bone allograft processing preserved non collagenous proteins, particularly proteoglycans, involved in growth factor availability, that were eliminated during Lubboc purification. This suggests that biomaterial impregnation by LMW fucoidan acts as a glycosaminoglycan alternative for heparin binding growth factor such as FGF2 [7], or TGF $\beta$ [28] and thus favours osteoblast performance.

In conclusion fucoidan in our experimental procedures stimulated expression of osteoblastic markers differentiation such as alkaline phosphatase activity, collagen type I expression and mineral deposition, furthermore cell proliferation was favoured. These findings suggest that fucoidan could be clinically useful for bone regeneration and bone substitute design.

Acknowledgements: We are grateful to Prof Sandrine Lorimier for help in scanning electron microscopy and to Mrs Kelly Godeau for checking our English. 


\section{$\underline{\text { References }}$}

1. Prolo DJ, Rodrigo JJ. Contemporary bone graft physiology and surgery. Clin Orthop Relat Res. 1985 ;(200):322-42.

2. Basle MF, Grizon F, Pascaretti C, Lesourd M, Chappard D. Shape and orientation of osteoblast-like cells (Saos-2) are influenced by collagen fibers in xenogenic bone biomaterial. J Biomed Mater Res. 1998 ;40(3):350-7.

3. Buck BE, Malinin TI. Human bone and tissue allografts. Preparation and safety. Clin Orthop Relat Res. 1994 ;(303):8-17.

4. Poumarat G, Squire P. Comparison of mechanical properties of human, bovine bone and a new processed bone xenograft. Biomaterials. 1993 ;14(5):337-40.

5. Feige JJ, Baird A. Crinopexy: extracellular regulation of growth factor action. Kidney Int Suppl. $1995 ;$ 49:S15-8.

6. Nardella A, Chaubet F, Boisson-Vidal C, Blondin C, Durand P, Jozefonvicz J. Anticoagulant low molecular weight fucans produced by radical process and ion exchange chromatography of high molecular weight fucans extracted from the brown seaweed Ascophyllum nodosum. Carbohydr Res. 1996 ;289:201-8.

7. Millet J, Jouault SC, Mauray S, Theveniaux J, Sternberg C, Boisson Vidal C, Fischer AM. Antithrombotic and anticoagulant activities of a low molecular weight fucoidan by the subcutaneous route. Thromb Haemost. $1999 ; 81(3): 391-5$.

8. Senni K, Gueniche F, Foucault-Bertaud A, Igondjo-Tchen S, Fioretti F, ColliecJouault S, Durand P, Guezennec J, Godeau G, Letourneur D. Fucoidan a sulfated polysaccharide from brown algae is a potent modulator of connective tissue proteolysis. Arch Biochem Biophys. 2006 ; 445(1):56-64. 
9. Senni K, Pellat B, Gogly B, Blondin C, Jozefonvicz J, Letourneur D, Colliec-Jouault S, Durand P, Sinquin C. Use of fucane for regulating the reconstruction of connective tissue. US patent No.6559131, 2003.

10. Matou S, Helley D, Chabut D, Bros A, Fischer AM. Effect of fucoidan on fibroblast growth factor-2-induced angiogenesis in vitro. Thromb Res. 2002 ;106(4-5):213-21.

11. Luyt CE, Meddahi-Pelle A, Ho-Tin-Noe B, Colliec-Jouault S, Guezennec J,Louedec L, Prats H, Jacob MP, Osborne-Pellegrin M, Letourneur D, Michel JB. Lowmolecular-weight fucoidan promotes therapeutic revascularization in a rat model of critical hindlimb ischemia. J Pharmacol Exp Ther. 2003 ;305(1):24-30.

12. Lake AC, Vassy R, Di Benedetto M, Lavigne D, Le Visage C, Perret GY, Letourneur D. Low molecular weight fucoidan increases VEGF165-induced endothelial cell migration by enhancing VEGF165 binding to VEGFR-2 and NRP1. J Biol Chem. 2006 ;281(49):37844-52.

13. Chabut D, Fischer AM, Helley D, Colliec S. Low molecular weight fucoidan promotes FGF-2-induced vascular tube formation by human endothelial cells, with decreased PAI-1 release and ICAM-1 downregulation. Thromb Res. 2004;113(1):93-5.

14. Beresford JN, Graves SE, Smoothy CA. Formation of mineralized nodules by bone derived cells in vitro: a model of bone formation? Am J Med Genet. 1993 ;45(2):16378.

15. Nefussi JR, Brami G, Modrowski D, Oboeuf M, Forest N. Sequential expression of bone matrix proteins during rat calvaria osteoblast differentiation and bone nodule formation in vitro. J Histochem Cytochem. 1997 ;45(4):493-503.

16. Aronow MA, Gerstenfeld LC, Owen TA, Tassinari MS, Stein GS, Lian JB. Factors that promote progressive development of the osteoblast phenotype in cultured fetal rat calvaria cells. J Cell Physiol. 1990 ;143(2):213-21. 
17. Logeart D, Letourneur D, Jozefonvicz J, Kern P. Collagen synthesis by vascular smooth muscle cells in the presence of antiproliferative polysaccharides. J Biomed Mater Res. $1996 ; 30(4): 501-8$.

18. Holden CM, Bernard GW. Ultrastructural in vitro characterization of a porous hydroxyapatite/bone cell interface. J Oral Implantol. 1990;16(2):86-95.

19. Schoeters G, Leppens H, Van Gorp U, Van Den Heuvel R. Haemopoietic long-term bone marrow cultures from adult mice show osteogenic capacity in vitro on 3dimensional collagen sponges. Cell Prolif. 1992 ;25(6):587-603.

20. Begley CT, Doherty MJ, Hankey DP, Wilson DJ. The culture of human osteoblasts upon bone graft substitutes. Bone. 1993 ;14(4):661-6.

21. Ishaug SL, Crane GM, Miller MJ, Yasko AW, Yaszemski MJ, Mikos AG. Bone formation by three-dimensional stromal osteoblast culture in biodegradable polymer scaffolds. J Biomed Mater Res. 1997 ;36(1):17-28.

22. Habibovic P, Yuan H, van der Valk CM, Meijer G, van Blitterswijk CA, de Groot K. 3D microenvironment as essential element for osteoinduction by biomaterials. Biomaterials. 2005 ;26(17):3565-75.

23. LeGeros RZ, Craig RG. Strategies to affect bone remodeling: osteointegration. J Bone Miner Res. 1993 ;8 Suppl 2:S583-96.

24. Jager M, Fischer J, Schultheis A, Lensing-Hohn S, Krauspe R. Extensive H(+) release by bone substitutes affects biocompatibility in vitro testing. J Biomed Mater Res A. 2006;76(2):310-22.

25. Anselme K. Osteoblast adhesion on biomaterials. Biomaterials. 2000 ;21(7):667-81.

26. Grzesik WJ, Robey PG. Bone matrix RGD glycoproteins: immunolocalization and interaction with human primary osteoblastic bone cells in vitro. J Bone Miner Res. 1994;9(4):487-96. 
27. Hartl A, Bitzan P, Wanivenhaus A, Kotz R. Faster integration of human allograft bone than of the bovine substitute Lubboc: non-randomized evaluation of 20 cases with benign tumors or tumor-like conditions. Acta Orthop Scand. 2004 ;75(2):217-20.

28. McCaffrey TA, Falcone DJ, Vicente D, Du B, Consigli S, Borth W. Protection of transforming growth factor-beta 1 activity by heparin and fucoidan. J Cell Physiol. $1994 ; 159(1): 51-9$. 


\section{$\underline{\text { Legends }}$}

Figure 1 : Osteoblast proliferation in 2D culture with or without LMW fucoidan (control) added to the culture medium.

Figure 2: Alkaline phosphatase activity expressed by human osteoblasts in 2D culture with (d, e, f) or without (a,b,c, control) 10 $\mu \mathrm{g} / \mathrm{mL}$ of LMW fucoidan after 7 (a, d), 14 (b, e) and 30 $(\mathrm{c}, \mathrm{f})$ days of culture. Magnification $=52$.

Alkaline phosphatase activity was observed for cells from the 7th day of culture in the presence of fucoidan (d) while only from the 14th day of culture without LMW fucoidan (b), the higher activity being detected at 14 days of culture for osteoblasts in the presence of LMW fucoidan (e).

Figure 3 : Von Kossa's staining and type I collagen expression by human osteoblasts in 2D culture with (d, e, f) or without (a,b,c, control) 10 $\mu \mathrm{g} / \mathrm{ml}$ of LMW fucoidan.: Von Kossa's staining after 30 days (a, d), Von Kossa's staining after 45 days of culture (b, e), expression of collagen type I after 45 days of culture (c, f). Magnification $=52$ for all documents.

Without LMW fucoidan, until day 30 of culture Von Kossa staining was negative (5a), and only few nodules were positive after 45 days of culture (b). In the presence of LMW fucoidan, von Kossa staining was positive at 30 days of culture (d) and after 45 days of culture von Kossa staining was intense (e).

Indirect immunodetection of collagen type I was positive and localised at the cell periphery after 45 days of culture for osteoblasts cultured without LMW fucoidan (c) and also for osteoblasts cultured in the presence of LMW fucoidan (f), the collagen labelling being superimposed with von Kossa's staining.

Figure 4: Scanning electron microscopy of bone biomaterial (Lubboc). a: at Low magnification $(\mathrm{G}=65)$. b: at higher magnification $(\mathrm{G}=9600)$.: The biomaterial appeared as connected trabecules with empty medullar spaces (a).: The biomaterial appeared with regular arrangement of collagen bundles(b)

Figure 5 : Scanning electron microscopy of bone biomaterial with or without fucoidan pretreatment cultured with human osteoblasts. Without LMW fucoidan at 10 days (a) and at 30 days (c). With LMW fucoidan at 10 days (b) and 30 days (d, f). Cellular density of biomaterial with or without fucoidan after 8 and 30 days estimated after collagenase treatment to detach cells from bone biomaterial (e). 
At 10 days of culture without pre-treatment with fucoidan osteoblasts displayed elongated shape (a), with pre-treatment with fucoidan osteoblasts developed numerous filopodia (b). At 30 days of culture without pre-treatment with LMW fucoidan the biomaterial surface was covered with osteoblasts (c), with pre-treatment with LMW fucoidan, the surface of the biomaterial is covered with a continuous sheet of osteoblasts (d), and osteoblasts made their way into the biomaterial (f).

Figure 6 : Indirect immunodetection of collagen type I with human osteoblasts in 3D culture, after 30 days of culture with (b) or without (a) LMW fucoidan. Magnification $=126$. Without LMW fucoidan only a weak positivity is detected(a). With LMW fucoidan collagen type I appeared clearly positive $(\rightarrow)$ at the periphery of the biomaterial (b).

Figure 7: Western blotting of osteocalcin secreted in the culture medium by human osteoblasts in $3 \mathrm{D}$ culture after $8,15,30$ and 45 days of culture with (f) or without (c) LMW fucoidan.

Osteocalcin was detected by western blotting in the culture media and appeared as a band at about $10 \mathrm{kDa}$. For osteoblasts cultured on pre-treated biomaterial with LMW fucoidan the intensity of the band decreased regularly with the culture time (from day 7 to day 45 of culture). The same observation was made with osteoblasts cultured on non pre-treated biomaterial the osteocalcin being detected clearly only at day 15 of culture.

Figure 8: Indirect immunodetection of BMP2 receptor with human osteoblasts in 3D culture, after 7 days of 3D culture with $(b, c)$ or without (a) LMW fucoidan. Magnification $=$ 126.

With the biomaterial without pre-treatment with fucoidan after 7 days of 3D culture a faint labelling was observed for BMP2 receptor (a) and for the biomaterial pre-treated with LMW fucoidan after 7 days of 3D culture a net labelling is observed associated with the cells at the periphery $(\rightarrow)$ of the biomaterial (b) and in the infrastructures of the biomaterial $(*)$ (c) for $\mathrm{BMP} 2$ receptor. 


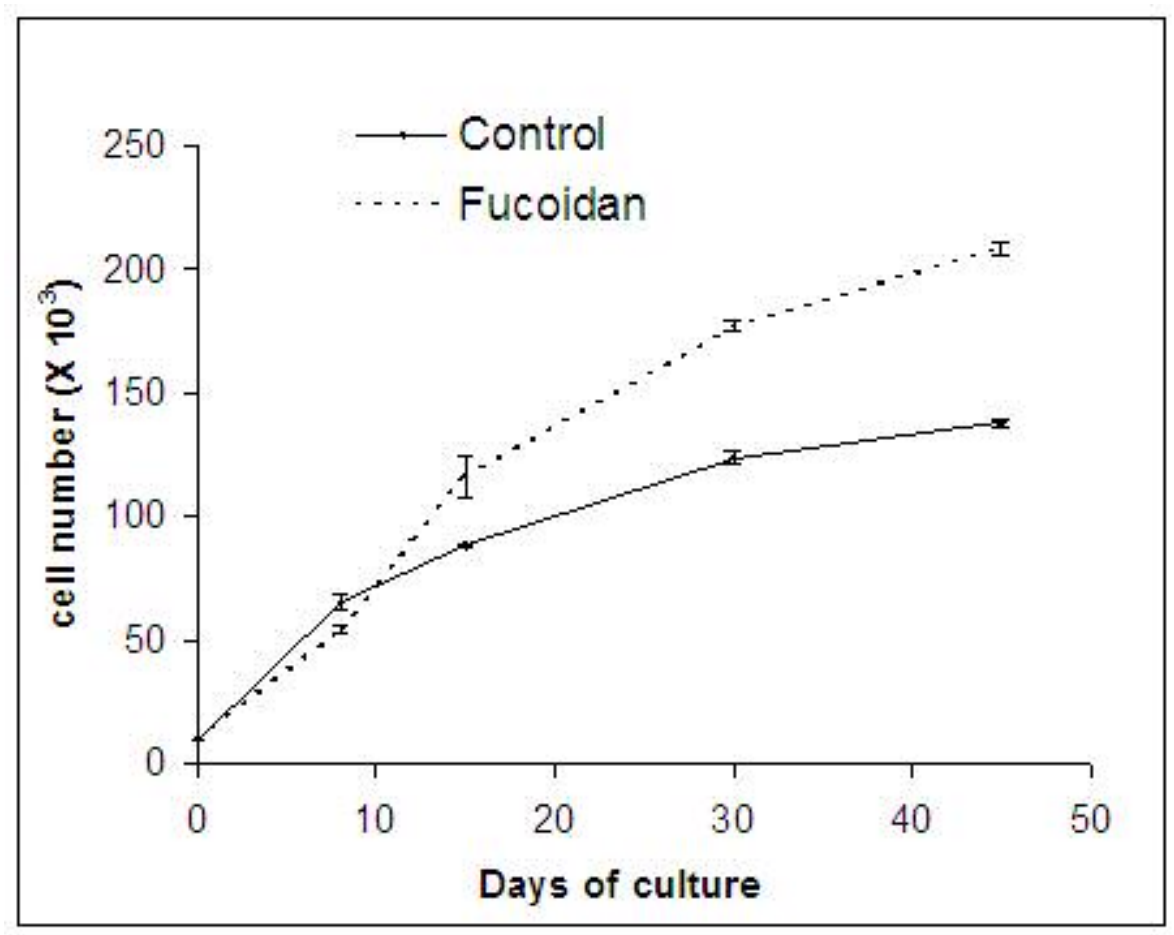

Figure 1: Osteoblast proliferation in 2D culture with or without LMW fucoidan (control) added to the culture medium.

John Wiley \& Sons, Inc. 


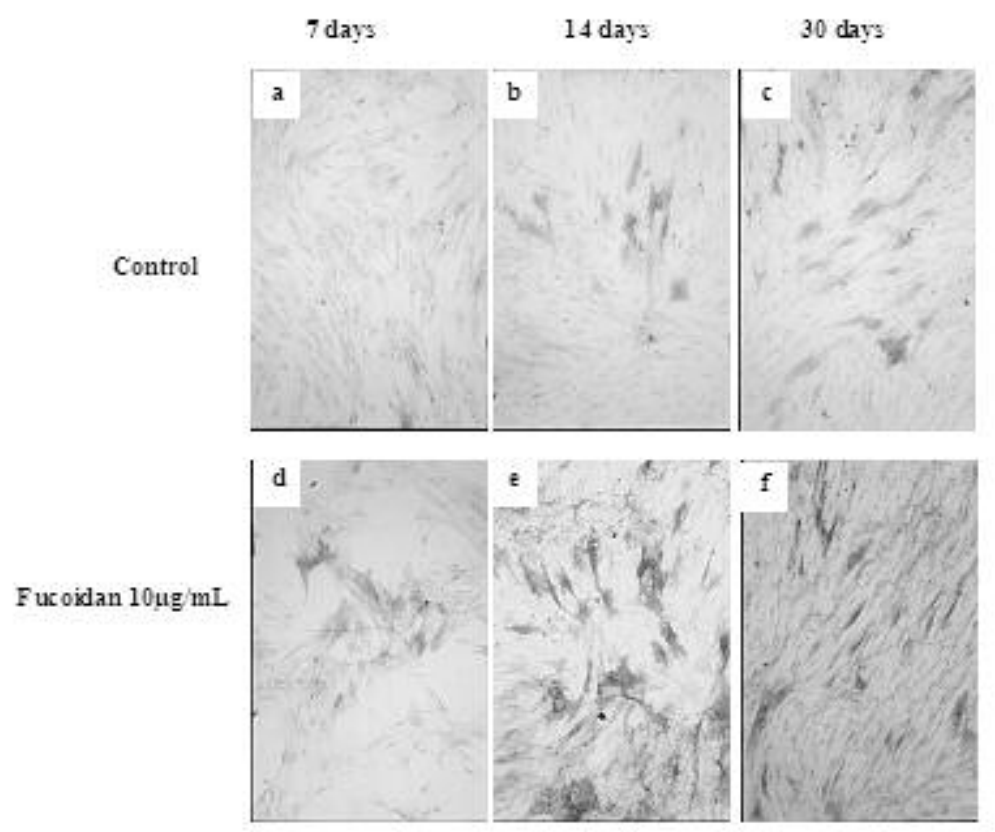

Figure 2: Alkaline phosphatase activity expressed by human osteoblasts in 2D culture with $(d, e, f)$ or without $(a, b, c$, control) $10 \mu g / m L$ of LMW fucoidan after $7(a, d), 14(b, e)$ and $30(c, f)$ days of culture. Magnification = 52. Alkaline phosphatase activity was observed for cells from the 7th day of culture in the presence of fucoidan (d) while only from the 14th day of culture without LMW fucoidan (b), the higher activity being detected at 14 days of culture for osteoblasts in the presence of LMW fucoidan (e). 
Von Kossa's staining
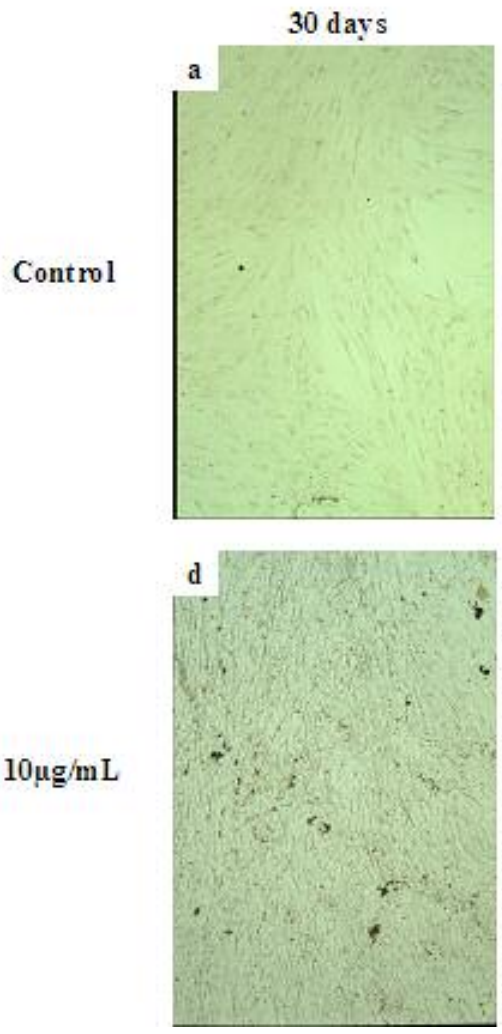

Type I collagen expression
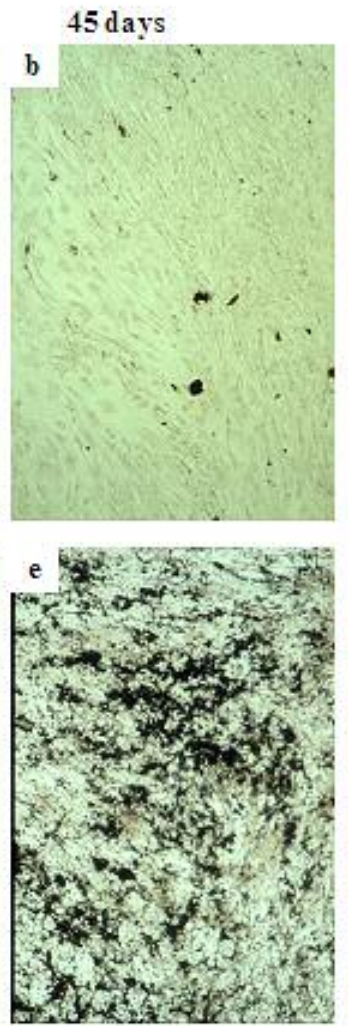
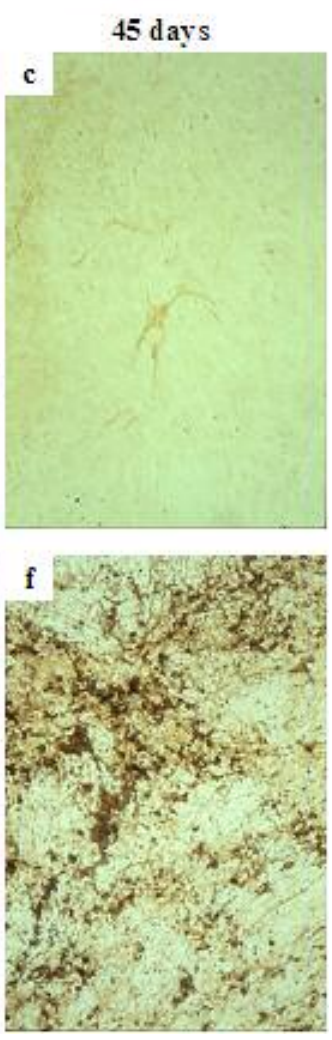

Figure 3 : Von Kossa's staining and type I collagen expression by human osteoblasts in 2D culture with (d, e, f) or without ( $a, b, c$, control) $10 \mu \mathrm{g} / \mathrm{ml}$ of LMW fucoidan.: Von Kossa's staining after 30 days $(a, d)$, Von Kossa's staining after 45 days of culture $(b, e)$, expression of collagen type I after 45 days of culture $(c, f)$. Magnification $=\mathbf{5 2}$ for all documents. Without LMW fucoidan, until day $\mathbf{3 0}$ of culture Von Kossa staining was negative (5a), and only few nodules were positive after 45 days of culture (b). In the presence of LMW fucoidan, von Kossa staining was positive at $\mathbf{3 0}$ days of culture (d) and after 45 days of culture von Kossa staining was intense (e). Indirect immunodetection of collagen type I was positive and localised at the cell periphery after $\mathbf{4 5}$ days of culture for osteoblasts cultured without LMW fucoidan (c) and also for osteoblasts cultured in the presence of LMW fucoidan (f), the collagen labelling being superimposed with von Kossa's staining. 

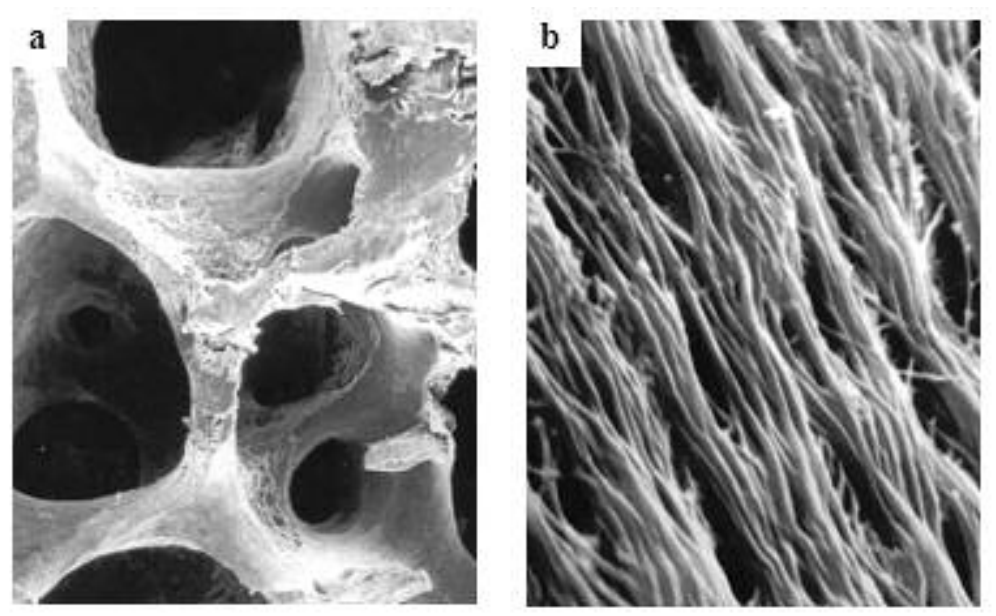

Figure 4: Scanning electron microscopy of bone biomaterial (Lubboc). a: at Low magnification $(G=65)$. $b$ : at higher magnification $(G=9600)$.: The biomaterial appeared as connected trabecules with empty medullar spaces (a).: The biomaterial appeared with regular arrangement of collagen bundles(b) 

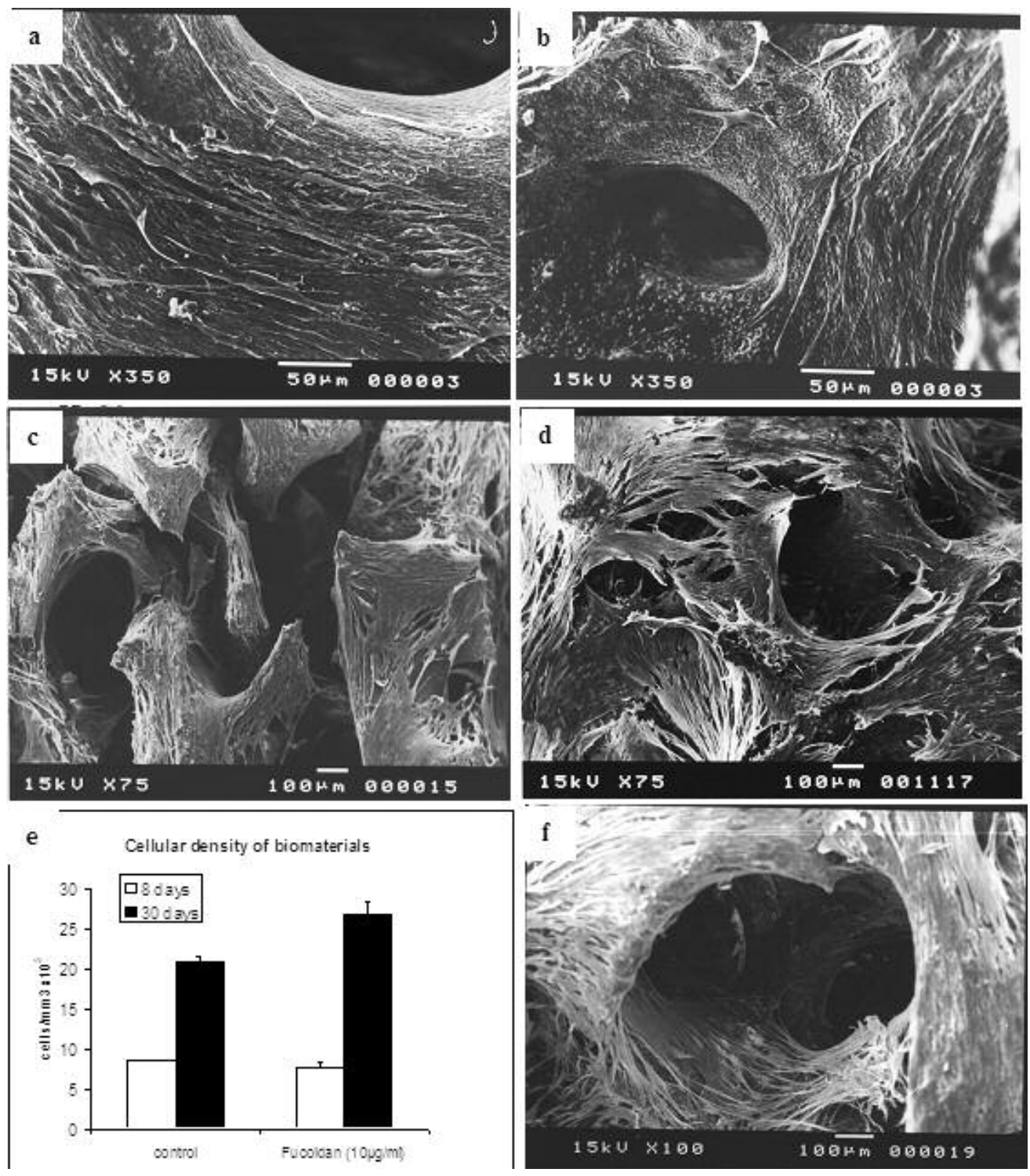

Figure 5 : Scanning electron microscopy of bone biomaterial with or without fucoidan pretreatment cultured with human osteoblasts. Without LMW fucoidan at 10 days (a) and at 30 days (c). With LMW fucoidan at 10 days (b) and 30 days (d, f). Cellular density of biomaterial with or without fucoidan after 8 and $\mathbf{3 0}$ days estimated after collagenase treatment to detach cells from bone biomaterial (e). At 10 days of culture without pretreatment with fucoidan osteoblasts displayed elongated shape (a), with pre-treatment with fucoidan osteoblasts developed numerous filopodia (b). At $\mathbf{3 0}$ days of culture without pre-treatment with LMW fucoidan the biomaterial surface was covered with osteoblasts (c), with pre-treatment with LMW fucoidan, the surface of the biomaterial is covered with a continuous sheet of osteoblasts (d), and osteoblasts made their way into the biomaterial ( $f$ ). 

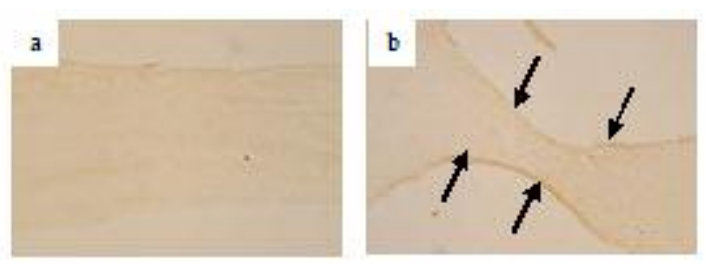

Figure 6 : Indirect immunodetection of collagen type I with human osteoblasts in 3D culture, after 30 days of culture with (b) or without (a) LMW fucoidan. Magnification = 126. Without LMW fucoidan only a weak positivity is detected(a). With LMW fucoidan collagen type I appeared clearly positive $(\mathbb{B})$ at the periphery of the biomaterial (b). 


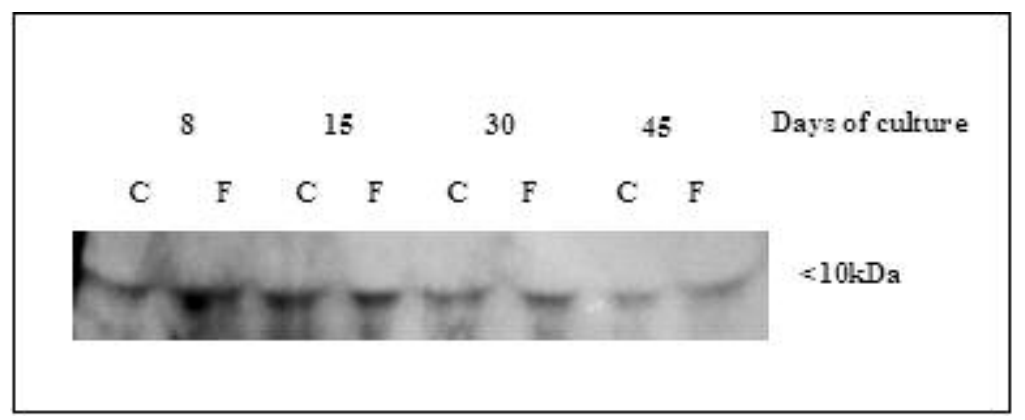

Figure 7: Western blotting of osteocalcin secreted in the culture medium by human osteoblasts in 3D culture after 8, 15, 30 and 45 days of culture with (f) or without (c) LMW fucoidan. Osteocalcin was detected by western blotting in the culture media and appeared as a band at about $10 \mathrm{kDa}$. For osteoblasts cultured on pre-treated biomaterial with LMW fucoidan the intensity of the band decreased regularly with the culture time (from day $\mathbf{7}$ to day $\mathbf{4 5}$ of culture). The same observation was made with osteoblasts cultured on non pre-treated biomaterial the osteocalcin being detected clearly only at day 15 of culture. 

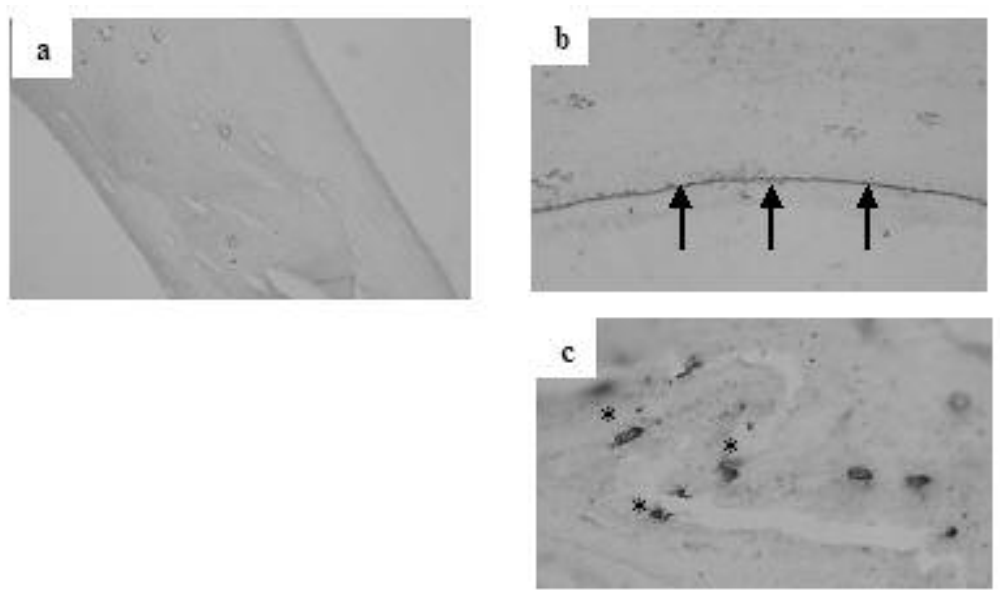

Figure 8 : Indirect immunodetection of BMP2 receptor with human osteoblasts in 3D culture, after 7 days of 3D culture with $(b, c)$ or without (a) LMW fucoidan. Magnification $=126$. With the biomaterial without pre-treatment with fucoidan after 7 days of 3D culture a faint labelling was observed for BMP2 receptor (a) and for the biomaterial pretreated with LMW fucoidan after 7 days of 3D culture a net labelling is observed associated with the cells at the periphery $(\mathbb{B})$ of the biomaterial $(b)$ and in the infrastructures of the biomaterial $(*)$ (c) for BMP2 receptor. 